\title{
FIRST RECORD OF THE FRUIT FLY, DIARRHEGMA MODESTUM (FABRICIUS) (DIPTERA: TEPHRITIDAE) FROM BANGLADESH
}

\author{
M. Aftab Hossain and Shakil A. Khan \\ Insect Biotechnology Division, Institute of Food and Radiation Biology \\ Atomic Energy Research Establishment, Savar, Dhaka-1349, Bangladesh.
}

Fruit flies (Diptera: Tephritidae) are the world's most devastating insect pests of horticultural crops. Besides causing damage to wide variety of fruits, vegetables and flower crops, they limit the development of agriculture in many countries because of the strict trade quarantines imposed to prevent their spread. About 70 species of fruit flies are considered important agricultural pests, and many others are minor or potential pests (White and Elson-Harris 1992). Alam (1967) reported 10 tephritid fruit flies from Bangladesh (East Pakistan). Kapoor et al. (1980) recorded 11 tephritid fruit flies from Bangladesh. However, there is no published report on the occurrence of Diarrhegma modestum (Fabricius) from Bangladesh. This species has been reported only from India (West Bengal, Karnataka and Tamil Nadu) where it breeds in the pods of drumstick, Moringa oleifera Lam. (Family: Moringaceae) used as vegetable in India (Hancock and Drew 1994). The fruit fly has also been recorded to breed in decaying wood (Bezzi 1913).

Four adult flies of both sexes were collected during May-June, 2012 from the ribbed gourd, Luffa acutungula (L.) Roxb., in a field of the Atomic Energy Research Establishment housing colony Campus, Ganakbari, Savar, Dhaka (23059"N, 9016"E). Various cucurbit crops, viz. Cucurbita maxima Duchesne ex. Lam., Trichosanthus cucumerina L. and Luffa acutungula along with a considerable amount of drumstick (Moringa oleifera Lam.) were cultivated in this field. The collected fruit flies were carried to the fruit fly laboratory, Insect Biotechnology Division, Institute of Food and Radiation Biology, Atomic Energy Research Establishment, Ganakbari, Savar, Dhaka-1349, Bangladesh. Each fruit fly was kept in a eppendorf tube containing $70 \%$ ethanol for preservation. The preserved fruit flies were sent to Dr. Allen L. Norrbom, Systematic Entomology laboratory, United States Department of Agriculture, Washington DC 20013-7012, USA for identification. Specimens of the fruit fly were also collected from Gurudaspur Upazila of Natore district and Regional Horticultural Research Centre, Chapainawabgonj in 2013.

Dr. A. L. Norrbom identified the specimens that were sent to him as Diarrhegma modestum which has not been reported from Bangladesh before. 
Though this species was collected from three different areas of the country, but this fruit fly may occur in other parts of Bangladesh.

On average, the female (plate 1) of the D. modestum was $6.25 \mathrm{~mm}$ and the male was $5.20 \mathrm{~mm}$ long. In the same way, the female wing was $5.25 \mathrm{~mm}$ and the male wing was $5.0 \mathrm{~mm}$ long. Antenna short with plumose arista; 6 scutellar bristles; only veins $\mathrm{R}_{1}$ and $\mathrm{R}_{4+5}$ setose above; Ovipositor comparatively short. The keys for the identification of $D$. modestum (Kapoor 1993) are as follows:

Two strong subequal apical spurs on mid tibia; a large white mark covers scutellum and hind portion of mesonotum Diarrhegma Bezzi Well developed hyaline wing markings and black abdominal bands on at least terga II to IV in both sexes; males specially have reduced bands (plate 2)

D. modestum (Fabricius)

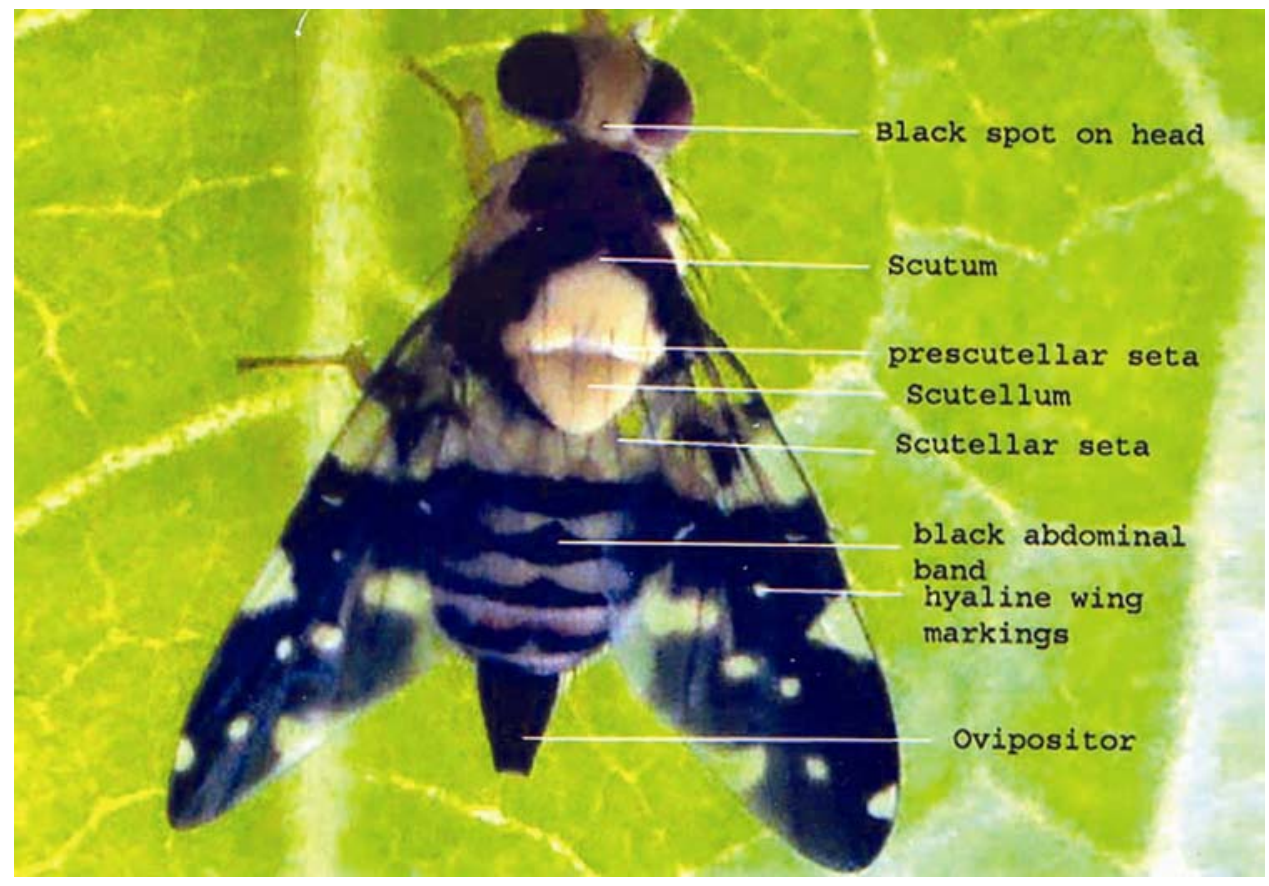

Plate 1. Diarrhegma modestum (female) on ribbed gourd leaf showing diagnostic characters

In India, D. modestum is a polyphagous pest of drumstick. Since the weather condition of Bangladesh is more or less similar to that of the drumstick producing provinces, there is a great possibility of $D$. modestum to become a potential pest of drumstick in Bangladesh. 


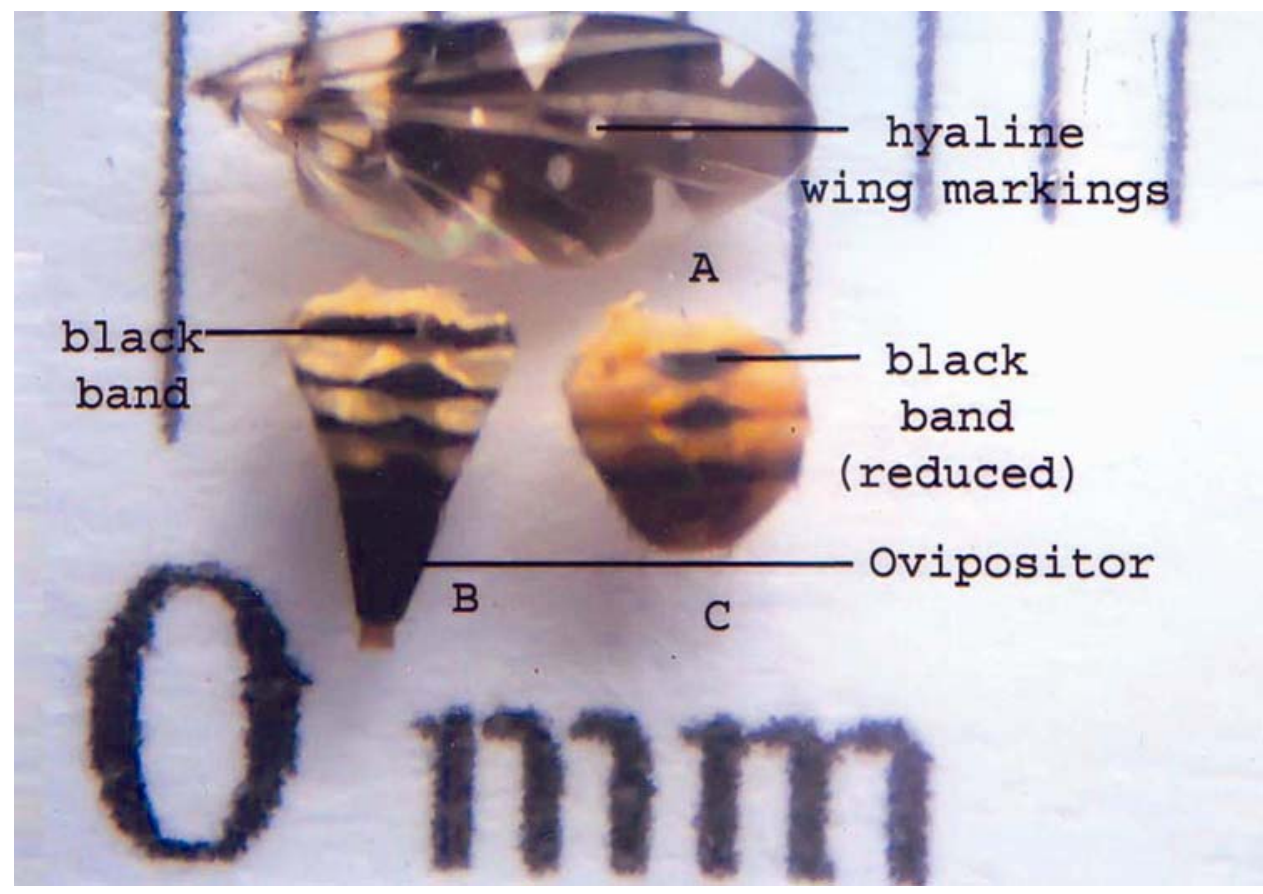

Plate 2. (A) Wing showing hyaliae markiage, (B) Absomen of female, (c) Abdomen of male

Acknowledgements: The authors are grateful to Dr. Allen L. Norrbom, Systematic Entomology laboratory, United States Department of Agriculture, Washington DC 20013-7012, USA for identification of the fruit fly, D. modestum (Fabricius).

\section{LITERATURE CITED}

ALAM, M. Z. 1967. A report on the survey of insect and mite fauna of East Pakistan. East Pakistan Agricultural Research Institute, Dhaka. 151pp.

BEZZI, M. 1913. Indian Trypaneids (fruit flies) in the collection of the Indian Museum, Calcutta. Mem. Ind. Mus. 3: 53-175.

HANCOCK, D. L. and Drew, R. A. I. 1994. New species and records of Asian Trypetinae (Diptera: Tephritidae). Raffles Bull. Zool. 42: 555-591.

KAPOOR, V. C. 1993. Indian Fruit flies (Insecta: Diptera: Tephritidae). Oxford and IBH Publishing Company, New Delhi. 228 pp.

KAPOOR, V. C., HARDY, D. E. AGARWAL, M. L. and GREWAL, J. S. 1980. Fruit fly (Diptera: Tephritidae) systamatics of the Indian subcontinent. Export India Publications, Jullundur, India. 113 pp.

WHITE, I. M. and ELSON-HARRIS, M. 1992. Fruit Flies of Economic Significance: Their Identification and Bionomics. International Institute of Entomology, London. 601 pp. 